\title{
Discussion of Environmental Audits Key Elements and Its Concept
}

\author{
Shutian Tai ${ }^{1} \&$ Chuanlian Song ${ }^{2}$ \\ ${ }^{1}$ The finance office, Changchun University of Science and Technology, Changchun 130022, China \\ ${ }^{2}$ College of Optical And Electronical Information Changchun University of Science and Technology, Changchun \\ University of Science and Technology, Changchun 130022, China \\ Correspondence: Chuanlian Song, College of Optical And Electronical Information Changchun University of \\ Science and Technology ,Changchun University of Science and Technology, Changchun 130022, China. E-mail: \\ chuanliansong@163.com
}

Received: February 22, 2013

Accepted: March 6, 2013

Online Published: March 7, 2013

doi:10.5430/bmr.v2n1p88

URL: http://dx.doi.org/10.5430/bmr.v2n1p88

The article is the phase fruit of the Project of Ministry of Education in 2012 entitled "Research on China environmental audit immunity from the perspective of public accountability". (Item No. 12YJA630100).

\begin{abstract}
In China, many specialists and scholars have made discussion on the concept of environmental audit, but because there are controversies about some key elements that form concept, there are great differences about the concept of environmental audit. The theoretical research of environmental audit lags behind, which seriously influences the launch of environmental audit practice. In the article, starting from the review of the current situation of the concept of environmental audit, the authors reveal the differences between concepts and answer the key questions involved in the concept of environmental audit, and discuss the definition of the concept of environmental audit according to the basic principles that theory serves practice.
\end{abstract}

Keywords: Environmental audit, Track, Environmental cost control

Concept is generally accepted and determined aggregation of meanings or characteristics related to event, object, condition, environment and behavior, in other words, it is the mode of thinking reflecting the essential attributes of events. (Du, Baoyou. 2005) Concept is the result of thinking, and also the starting point and basis of thinking. Using concept is able to make the communication between people convenient greatly. (Chen, Hong'an \& Jiang, Ruochen. 2010) In China, many specialists and scholars have made discussion on the concept of environmental audit, but because there are controversies about some key elements that form concept, there are great differences about the concept of environmental audit. Audit is a kind of relationship, which is a behavior that audit subjects accept delegation or authorization to supervise audit object. Based on the definition of concept, using general concept of audit, discussing several key elements that form the concept of environmental audit is helpful to form the concept of environmental audit.

\section{Review of the research on the concept of environmental audit}

With respect to the concept of environmental audit, many Chinese scholars have made different comments. Zhang Yikuan (1996) thought environmental audit is economic supervision, economic authentication and economic evaluation activities carried by independent audit institutions and auditors focusing on the compliance, legitimacy and effectiveness of the behavior including that environmental managers formulae environmental protection provisions, implement environmental protection policy and environmental protection capital. It is an important part of environmental management system. (Zhang, Yikuan. 1996)

Chen, Siwei (1998) thought environmental audit is an auditing activities that auditing agency, internal audit institution and Certified Public Account (CPA) supervise, evaluate and authenticate environmental management system of the government and enterprise and public institution, and the environmental impact of economic activities, making them controlled positively and effectively, and conform to the requirements of sustainable development. (Zhang, Yikuan. 1996)

Bao Qiang (1999) shows environmental audit is a kind of independent economic supervision, economic management and economic evaluation activities including that audit organization investigates environmental problems of audited 
units in their economic activities according to the law, as well as the authenticity, legality and effectiveness of financial affairs and financial revenues and expenditures related to the economic activities in environmental management, evaluate economic responsibility, and reveal unlawful acts in order to promote them to strengthen environmental management and realize sustainable development. (Bao, Qiang. 1999)

Gao, Fanglu and $\mathrm{Wu}$, Junfeng (2000) thought, environmental audit, includes financial audit, compliance audit and performance audit, is a kind of control activity, which supervises responsible subjects over the performance of environmental responsibilities through examining responsible subjects' environmental report and environmental management activities, and evaluate and authenticate the status of performance, as well as provide advice about the environmental management problems put forward by responsible subjects, and thus realize the control of the process that responsible subject performance environmental responsibility. (Gao, Fanglu \& Wu, Junfeng. 2000)

Li Xue \& Yang Zhihui (2004) thought, environmental audit is that the government offices, internal audit institutions and social audit organizations authenticate the fairness, legitimacy and effectiveness of audited unites performance environmental responsibility according to environmental audit standards, in order to ensuring effective performance of commissioned environmental responsibility. (Li, Xue \& Yang, Zhihui. 2004)

From the concepts above we can see that scholars have unclear awareness about the essence and function of environmental audit; there are great differences about the subjects and objects of environmental audit; Avoid the key elements such as the standards and causes of environmental audit; they do not define environmental audit from China's practice of environmental audit so that the concept cannot serve practice...... discussion of several key elements about environmental audit currently in China is helpful to form the concept of environmental audit.

\section{The essence and main functions of environmental audit}

Regarding to the essence of environmental audit, the viewpoints of specialists and scholars have several aspects including evaluation, supervision, authentication and so on. The authors think they do not reveal the essence of environmental audit far away. At most they belong to the functions of environmental audit.

Quality and quantity are corresponding concepts, which are description of properties of an object. Essence is intrinsic and essential attribute that an object has. If the essence of environmental audit is evaluation, supervision or authentication, what is their fundamental aim? Or just to evaluate for evaluation, to supervise for supervision and to authenticate for authentication. Obviously, taking them as the essence of environmental audit lacks logic support.

Considering the primitive quality of environmental audit needs to combine the practice of economic development and consider historical backgrounds of environmental audit. Economic development cannot leave resource and environment. Because resource and environment are limited, people find that if they do not consider environmental protection, the cost of rapid economic development will be the generation and aggravation of pollution, environmental destruction and resource exhaust inevitably, and thus influence further economic development. If the problem about the relationship between economic development and environmental protection is processed badly, economic development will come into a closed loop. Meanwhile, environmental consequences brought by economic development also greatly influences human and their offspring's life quality. People begin to introspect the ultimate meaning of economic development. Currently, economic development needs to be kept sustainable. In the meantime of economic development, it also should be considered that human life level has been improved, which has obtained identification of various countries' specialists and scholars. But the core problem that economic sustainable development, economic development and human life coordinate is the sustainable use of resource. Environmental audit is put forward in the background.

Because of the externality characteristics of environmental cost, external economy and external diseconomy; internal economy and external diseconomy. Therefore, the environmental cost of economic development should take region as examination object and the government as the responsible persons environment.

In view of this, the authors think the essence of environmental audit is regional environmental cost control activity in order to keep economic and social sustainable development. Because of the particularity of environmental pollution, the treatment after pollution pattern cost more; therefore environmental cost control should keep tracking in total process, which means to follow-up audit and control in total process in the use environmental resource.

On the basis, the authors further discuss the functions of environmental audit. Function is the feature that an object has or the role it plays. Firstly, it should be explicit that the function of environmental audit is to keep the realization of the target of environmental audit essence. Resource users should include enterprises in general meaning and other economic organizations as well as individuals. In order to be convenient in the research, the article takes enterprise as an example to explain the use of resource. Because resource is owned by all the people, while the government is the 
nominal owner of all the people's assets, therefore, the roles of the government in the aspect of resource cost control are the authorization and permissive use of resource, the supervision before and after using resource.

From the sense to analyze, environmental audit should include the contents below: resource permissive use and examination and approval; environmental impact assessment of investment project; clean production audit of emprise and projects; enterprise environmental products certification; the legitimacy and fairness supervision of environmental management deed in environmental management department; the legitimacy and effectiveness supervision that environmental treatment capital is used. So the functions of environmental audit should include control, evaluation, supervision, authentication and so on. The fundamental target of the functions including evaluation, supervision and authentication is also to minimize environmental cost; therefore, in many function of environmental audit, environmental cost control is the fundamental function, while the control function is realized by ways of supervision, evaluation and authentication.

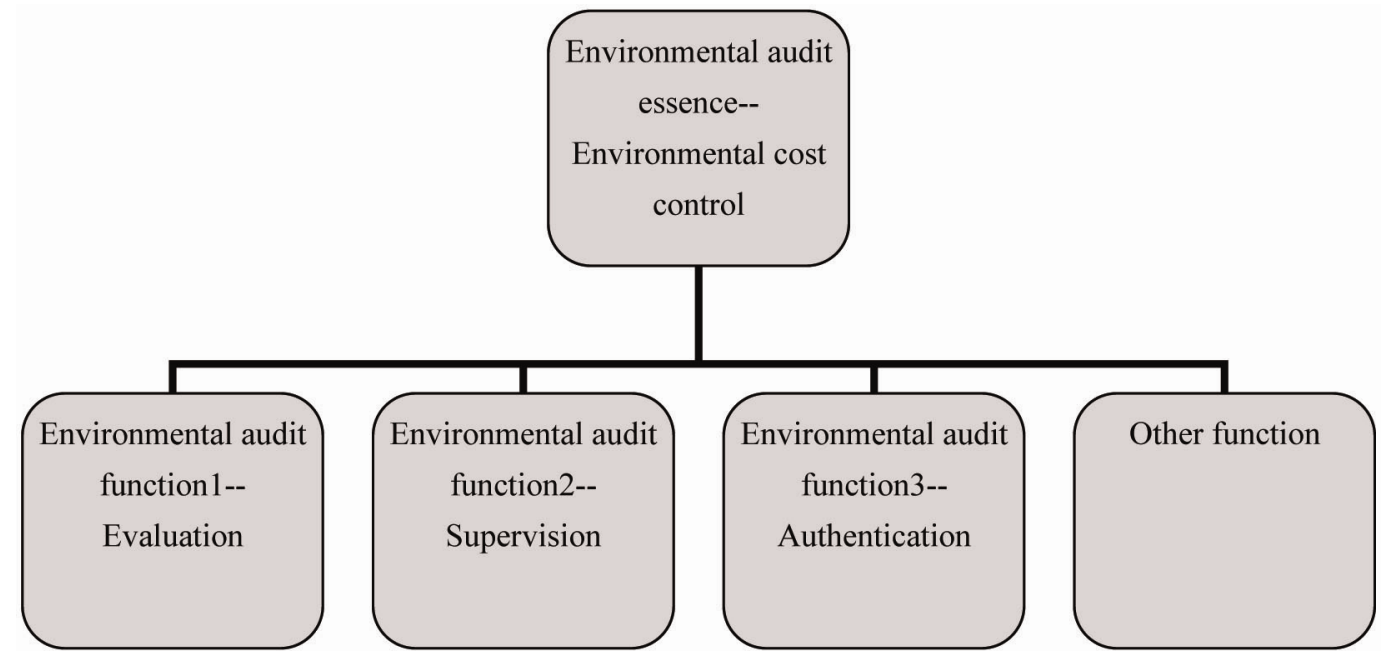

Figure 1. The diagram of environmental audit essence and functions

\section{The subject of environmental audit}

From the concept above it can be seen that most scholars think the subject of environmental audit should be the governmental audit, internal audit and social audit. To establish the Trinity environmental audit supervision system has been recognized by specialists. But the authors think the viewpoint of specialists has the problems below: 1) it does not point out who is predominant in the environmental audit supervision subjects; 2) besides the three subjects, whether there is the fourth supervision subject. For this, the authors will make a discussion in the article.

The subjects of environmental audit are the departments, organizations, institutions (organizational subject for short) or staff that fulfill environmental audit. Deferring the definition of the subject by other kinds of audit, the subjects of environmental auditing staff should be professional environmental auditors. From current situations, there has not been special environmental auditor authentication in China. Therefore in current situation, the subjects of environmental auditing staff should be professional auditing staff. Because of the universality of environmental impact behavior and the different independence of different subjects, the institutional subjects of environmental audit should include governmental audit department, internal audit institution and nongovernmental audit organizations. This point has been recognized by specialists. But different specialists and scholars have different viewpoints about who should play the leading role in the audit supervision system. The authors think because of the existence of the characteristics including the publicity of environmental resource, the externality of environmental cost and the specialty and imperceptibility of environmental pollution, China's environmental audit should be led by the governmental audit, taken nongovernmental audit as the main force and internal audit as the core to fully accept social supervision.

Specifically speaking, the types of environmental audit are different, and its supervision subjects should also be different. The supervision subject of the permissive use and examination and approval of the resource must be the government, because the permissive use of resource belongs to the duty of the government. To be audited by the government audit supervision department conforms to general provision that Chinese government audits and supervises the object currently; environmental impact assessment of invested project is performed by environmental protection department. Currently absence of corresponding supervision causes a great deal of undue consequence, 
making a lot of projects' environment impact assessment become formalistic. The auditing subject of environment impact assessment deed should be the governmental audit department or accounting firms delegated by the governmental audit department; the clean production audit of enterprise, projects plays important role in preventing, detecting and rectifying the pollution in the process of enterprise production, but it has not been carried out commonly. Although some provinces have carried out clean production audit with limits, they often become formalistic finally, lack of performance in the long run, whose reasons are multiple, among which the weakness of internal audit independence is the main reason. If clean production subject is executed by enterprise internal auditors, it is suggested that the governmental audit supervises the performance of the subject so as to strengthen its independence or the government send environmental audit supervision subjects to resident in the enterprise for supervision, and report their work to the governmental audit regularly, as well as accept social supervision at the same time; enterprise environmental production certification is the environmental audit mode easiest accepted by enterprises. The subject of environmental audit should be social audit force, but because the authority of social audit force is weaker than governmental audit, it is advised to adopt governmental audit to delegate social audit to finish environmental products certification audit; the supervision of the fairness and legitimacy of environmental management deed in environmental management depart should be performed by the governmental audit department; the legitimacy and effectiveness supervision that environmental treatment capital is used can be executed by governmental audit. The governmental audit also delegates social audit force to perform.

Overall, the subject of environmental audit and its specific supervision object should form independent relationship in order to confirm the realization of environmental audit effects.

Led by the governmental audit, getting full play of internal audit and social audit force to develop the role of the trinity audit supervision system is just theoretical discussion. In fact, the happen of environmental pollution has the characteristics including extensibility, imperceptibility and specialty. Only relying on three professional audit forces for supervision is not enough. Because of the high metric uncertainty of the elements such as environmental assets and environmental debt, in fact environmental accounting has not been implemented. In other words, current environmental audit is carried out in the premise lack of environmental accounting resource. Even though some enterprises have tried environmental accounting treatment, their measurement and confirmation of environmental assets and environmental debt are often incomplete. Therefore, the way to obtain evidence of environmental audit cannot be like the other audit types, which extensively adopt to the ways such as examination records and files and checking assets. Particularly for environmental pollution deed, the discovery of audit clue is very important. Based on the viewpoint, the authors think the subject of environmental audit should be defined further, which can be divided specifically: the discovery subject of environmental clue and the performance subject of environmental activities.

Specifically, professional environmental tip-off website should be built to encourage the public to inform environmental pollution deeds. And professional volunteer alliance is set up to popularize the common sense about environmental pollution in the alliance and more scale of people in society so as to supervise environmental consequence. Once pollution clue is detected, the governmental audit department should deal with it. For example it can delegate corresponding governmental audit department or social audit force to supervise.

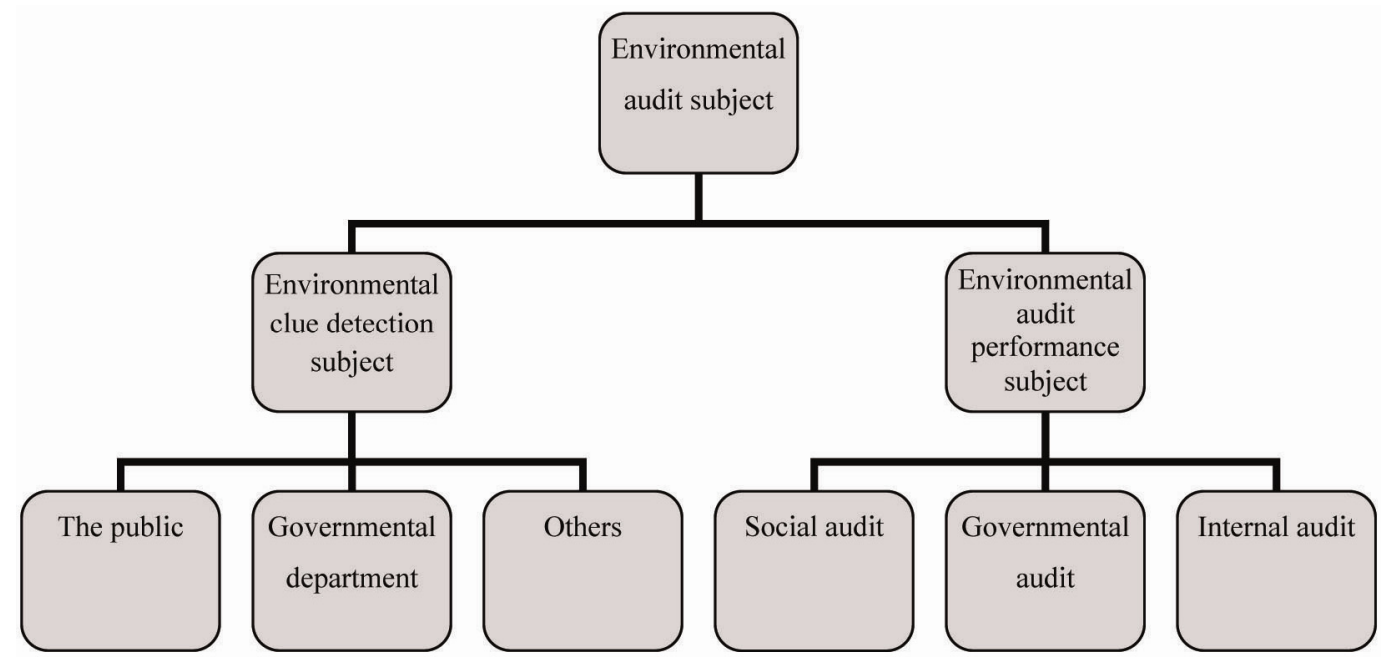

Figure 2. the diagram of environmental audit subjects 


\section{Environmental audit supervision object}

According to general definition of audit supervision object, the object of environmental audit should be economic activities related to the environment. But obviously, the definition is too extensive, which not only cannot meet the need defined by the concept of environmental audit, but is not beneficial to the launch of environmental audit practice. Once the consequence of environmental pollution happens, its responsibility is difficult to be confirmed; therefore, environmental audit should give priority to environmental cost control. Control obtains effects and the control behavior must be kept consistent. According to basic theory of enterprise business transaction procedure, complete transaction process should include the authorization of transaction, the performance of transaction, the record of transaction, the management of the assets obtained from the transaction, the supervision over the activities related to the transaction and so on. On basis of the theory, the authors defines the use of environmental resource as transaction, so the transaction also should include the authorization, use, record of the transaction, the storage of assets obtained from transaction, the confirmation of the debt formed in the transaction, the supervision over each link and so on.

For environmental resource, the authorization of resource belongs to the government. Firstly, the government allows certain enterprise to build. The enterprise has to select the site. Scientific site selection avoids out of control after environmental consequence happens in advance; therefore, the government must plan scientifically according to the characters of enterprise. For example, current proposal about national resource functional zone division is very suitable for the thinking of environmental cost control. But whether relevant departments fulfill the essence meaning of functional zones appropriately needs the supervision of environmental audit, which belongs to the supervision over transaction authorization; about whether the enterprise built after site selection is able to invest machinery equipment according to the requirement of minimizing environmental cost, currently the supervision the government performs it to carry out its environment impact assessment, which is executed by environmental protection department. Therefore, corresponding environmental audit subject should audit and supervise the execution department of environment impact assessment, and evaluate the reasonability of its environment impact assessment; after the project is invested and finished, whether pollution discharge equipment is sometimes open or closed, and whether the enterprise controls operating cost in order to save environmental cost should be also supervised, which belong to the scope of clean production audit; in order to arouse the initiative of enterprise environmental cost control, the production of the enterprise is carried out environmental quality certification; therefore, environmental quality authentication appears; if environmental cost is out of control, or the other reasons cause the item about environmental pollution treatment, the government should also invest fund to treat environmental pollution. The supervision over the real fairness that the environmental protection capital is used also belongs to the content of environmental audit.

In current environmental activities, the position of environmental protection department is very special. On the one hand, it belongs to governmental functional department, in charge of environmental management and environmental cost control and responsible for the supervision of environmental activities; on the other hand, environmental protection department is responsible for environment impact assessment, environmental capital collection and environmental pollution treatment. Therefore, it also belongs to environmental items performance department, and should accept supervision theoretically. Therefore, what is called supervision over supervision is to re-supervise the environmental supervision act of environmental protection department, which is also behavior that takes environmental protection department as a link of environmental business process to audit and supervise.

But because of the difficulty in calculating environmental resource, current environmental activities cannot form complete accounting records. Therefore, the object of environmental audit supervision sometimes does not include the record of environmental resource and debt.

Some specialists and scholars think the object of environmental audit supervision should include the formulation of environmental laws, but the authors disagree with them. Because in China, environmental audit is a performance department only, the alteration of law does not belong to its supervision scope. The discussion of the authors is under the supervision of current law frame. 


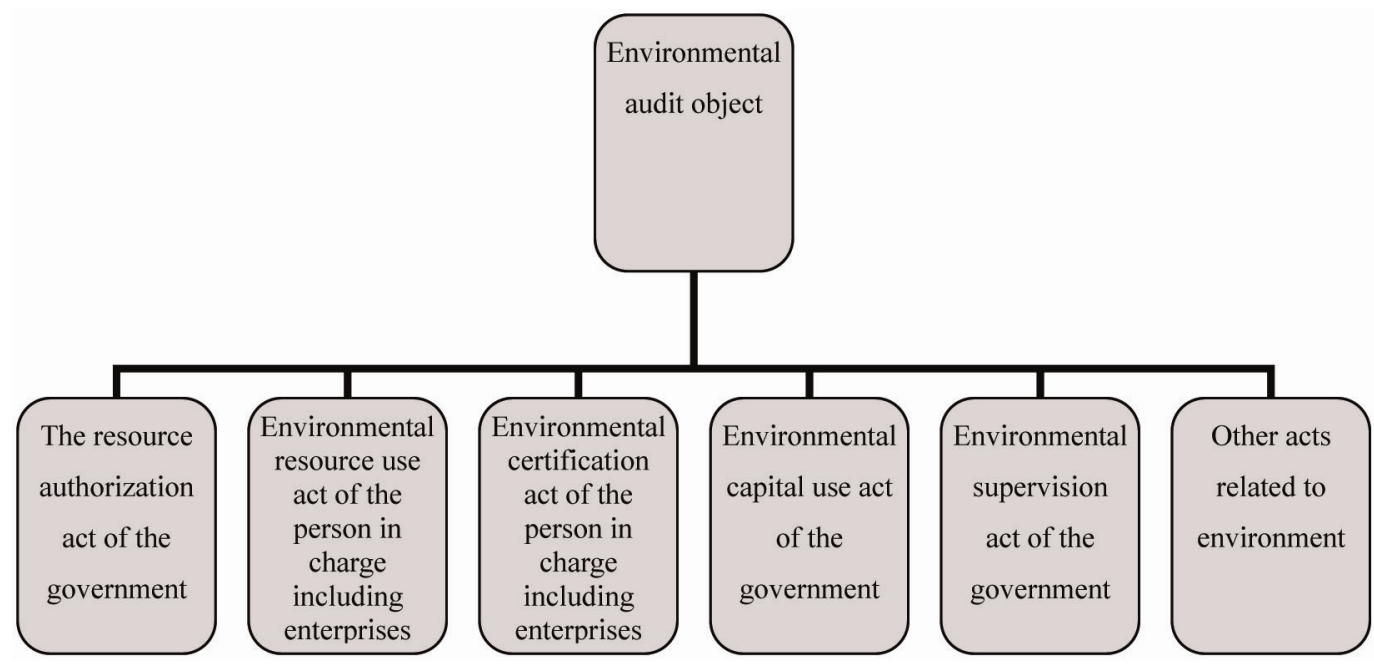

Figure 3. the diagram of environmental audit object

\section{The standards of environmental audit}

Regarding to the standards of environmental audit, some scholars avoid it, while some others think it is environmental audit principle, but China has not issued professional environmental audit principle until now; therefore some scholars think environmental audit has no defined standard. The viewpoints inevitably lead environmental audit to be nothing. The viewpoint of the authors is that China's environmental audit has obtained current standards. But for different environmental audit acts, the stands are also different.

According to our discussion, the contents of environmental audit include: resource permissive use and examination and approval; environmental impact assessment of investment project; clean production audit of emprise and projects; enterprise environmental products certification; the legitimacy and fairness supervision of environmental management deed in environmental management department; the legitimacy and effectiveness supervision that environmental treatment capital is used. Accordingly, different business links have different legal restraints. Enterprise environmental products certification is performed according to ISO 4000 management standard currently. Therefore, environmental audit should examine the compliance, legitimacy, reasonability and effectiveness of the acts according to relevant standards. Of course, in the long run, the standards also need to be adjusted so as to become more reasonable.

\section{The definition of the concept of environmental audit}

In the premise that the subject, object, target, function and client of environmental audit are fully explicit, combined with China's practical situations, the authors define the concept of environmental audit.

Environmental audit is a kind of management activities centralized on environmental cost control carried by the government, in order to ensure environmental resource sustainable use based on public accountability of environmental resource; specifically speaking, it is corresponding environmental audit subjects accept delegation or authorization to supervise, evaluate and authenticate the legitimacy, fairness, compliance and effectiveness of the behavior focusing on the authorization, use and management of environmental resource according to certain standards.

\section{References}

Bao, Qiang. (1999). Discussion on the concept structure of environmental audit. Journal of Audit and economics. No. 4.

Chen, Hong'an \& Jiang, Ruochen. (2010). Enterprise studies methods. Higher education publishing house.

Du, Baoyou. (2005). General Logic Tutorial. Beijing Publishing House.

Gao, Fanglu \& Wu, Junfeng. (2000). Research on the essence contents of environmental audit. Journal of Guizhou College of Finance and Economics. No. 2.

Li, Xue \& Yang, Zhihui. (2004). Re-understanding of the definition of environmental audit. Journal of Nanjing Audit University. No. 1.

Qi, Xiao'an. (2000). Research on several problems about China's economy. Jilin University publishing house. No. 6.

Zhang, Yikuan. (1996). Discuss on environmental audit. Communication of Finance and Accounting. No. 6. 